Weather and oceanographic processes that are not linked to storms cause sea levels to rise over weeks to months, but their effects have been overlooked in models of beach erosion. So Ethan Theuerkauf and his colleagues at the University of North Carolina's Institute of Marine Sciences in Morehead City studied sediment cores from six sites along Onslow Beach on the US east coast after a year of frequent sealevel changes but no major storms. They compared these cores with those obtained after a storm year and found similar levels of erosion.

The authors suggest that sealevel changes could become more frequent in this region because climate change is predicted to weaken the Gulf Stream, which can lead to these sea-level anomalies.

Geophys. Res. Lett. http://doi. org/ttn (2014)

\section{IMMUNOLOGY}

\section{Inflammation on the clock}

An internal clock regulates inflammation in mouse lungs.

Symptoms of some human lung diseases, including asthma, tend to vary in severity according to the time of day. Andrew Loudon and David Ray at the University of Manchester, UK, and their colleagues found that immune responses to a bacterial toxin are regulated by a circadian clock in mouse lungs. The recruitment of immune cells called neutrophils and the expression of several immunerelated proteins responded rhythmically to the toxin, with neutrophil recruitment peaking at dawn.

Deleting a key 'clock gene' weakened responses to bacterial infection and reduced the effect of glucocorticoid steroids, which normally suppress inflammation. Chronic lung inflammation could be partly caused by circadian disruption, the authors say. Nature Med. http://dx.doi. org/10.1038/nm.3599 (2014)

\section{CLIMATE SCIENCE}

\section{Warming from coupled climates}

Links between the climate over the North Pacific and the North Atlantic oceans could lead to abrupt climate change.

Researchers have debated

whether temperature and ocean fluctuations were in sync with each other during past climate changes. Summer Praetorius and Alan Mix of Oregon State University in Corvallis studied oxygen isotopes as a proxy for ocean temperature in three sediment cores from the Gulf of Alaska covering the past 18,000 years.

By comparing the Alaska samples to cores from northern Greenland, the scientists found that climate variables such as temperature changed synchronously between about 15,500 and 11,000 years ago shortly before the end of the last ice age.

The authors suggest that this link could have shifted heat in both oceans towards the poles at the same time, triggering abrupt climate change. They add that similar connections may be important for future warming.

Science 345, 444-448 (2014)

\section{OPTICS}

\section{Transistor uses single photons}

Two teams in Germany have built transistors that control light at the single-photon level.

Transistors that switch

light instead of electrical current can enable ultrafast computing. But making optical transistors with 'gain' — when one photon affects many others to drive further switches - has been tricky because photons do not interact with each other.

To overcome this problem, a team at the Max Planck Institute of Quantum Optics in Garching and a separate group at the University of Stuttgart passed a single photon through a cloud of ultracold rubidium atoms.

SOCIAL SELECTION Rominartides

\title{
Beef's big impact on Earth
}

Beef is suddenly big on social media, thanks to two recent papers investigating the global effects of livestock farming. They make the case that beef production has a bigger impact on greenhouse-gas emissions and on the use of nitrogen and water than does the production of pork and poultry, for instance. Tim Thomson, a physician and molecular biologist at the Molecular Biology Institute of Barcelona in Spain, tweeted: "Do not imitate Americans: Eat less beef and you will mitigate environmental costs of diet." But Jared Decker, a beef-cattle geneticist at the University of Missouri in Columbia, tweeted that cattle have a relatively small carbon footprint compared to other industry sectors, adding: "Wouldn't changing transportation \& energy be more important?"

Clim. Change http://doi.org/tvw (2014); Proc. Natl Acad. Sci. USA http://doi.org/tvx (2014)

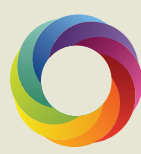

Based on data from altmetric.com. Altmetric is supported by Macmillan Science and Education, which owns Nature Publishing Group.
DNATURE.COM

For more on popular papers: go.nature.com/ajre5g
The photon converted one atom into a type of large, excited particle called a Rydberg atom, which blocked the next photon from passing through.

In the Stuttgart team's transistor, one photon diverted another 10, whereas in the Max Planck device, a photon controlled a further 20 .

Phys. Rev. Lett. 113, 053602

(2014); 113, 053601 (2014)

\section{EVOLUTION}

\section{Sperm are}

\section{speedier in groups}

In the face of competition, sperm cells travel faster when

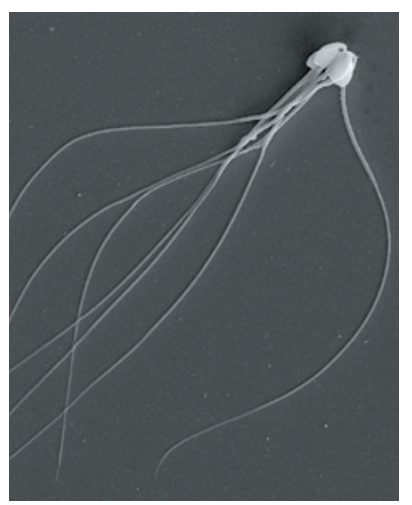

they move together in groups of an optimal size.

A team led by Heidi Fisher at Harvard University in Cambridge, Massachusetts, studied rodent sperm cells under a microscope, and used a mathematical model to analyse their swimming behaviour. They found that, in comparison to solitary sperm or those in larger groups, intermediate-sized aggregates of six or seven sperm (pictured) tend to migrate the fastest, by taking a more direct path.

Sperm cells from a sexually promiscuous species of deer mouse, Peromyscus maniculatus, were faster and more likely to form optimally sized clumps than were similarly shaped sperm from a monogomous sister species, Peromyscus polionotus.

The results show how sexual selection can shape the evolution of cooperation.

Proc. R. Soc. B 281, 20140296 (2014)

\section{$\rightarrow$ NATURE COM}

For the latest research published by Naturevisit:

www.nature.com/latestresearch 